\title{
Transformational Leadership and the Integration of Information and Communications Technology into Teaching
}

$\mathrm{Ng}$ Wee Leng

National Institute of Education, Nanyang Technological University, Singapore

weeleng.ng@nie.edu.sg

Information and communications technology (ICT) has now permeated nearly every facet of society and there is a growing need for school leaders to play a more active role in integrating ICT into teaching. While it is conceivable that transformational leadership, which has been found to be an essential form of leadership in dealing with challenges facing contemporary schools, has effects on efforts to implement school innovations such as ICT integration, to date no such study has been conducted. This study therefore field-tests a questionnaire designed to investigate teachers' perceptions of positive influence of transformational leadership practices on the integration of ICT into teaching.

Keywords: ICT, transformational leadership, teaching, school innovation

Does transformational leadership positively influence teachers to integrate information and communications technology (ICT) into teaching? This is an important question for school leaders who are, and will continue to be, key figures in efforts to leverage the strengths and the promise of ICT in offering a tremendous range of new learning opportunities for students. In this paper, we shall report on the development of a questionnaire which attempts to answer this question and a field test using this instrument.

ICT has pervaded almost every facet of our society. Around the world, ICT is ubiquitous in the business world, the workplace, and the home. To ensure that schools keep pace with these developments in the larger society and to tap the enormous potential of ICT in teaching and learning, many countries have invested considerable amounts of resources to integrate ICT into education. Singapore, for instance, had invested S\$2 billion between 1997 and 2002 to facilitate ICT integration in schools, spending mostly on hardware, software, infrastructure and training of teachers (Ministry of Education, 1997). In particular, by the year 2002, all serving teachers, regardless of age or number of years of service, had completed a series of training designed to prepare them to be proficient users of a word processing software application, a spreadsheet software application, and a presentation software application. With the equipment and infrastructure in place, the challenge now is for teachers to explore ways to use ICT in their teaching and, in turn, for school leaders to examine their roles in the integration of ICT into teaching and learning in schools. 
Integration of ICT into education, as Eib and Mehlinger (1998) define it, is a procedure in which instructional technologies such as computers and software are applied regularly to support both teaching and learning across levels and subject matter. There has been a significant amount of research devoted to the integration of ICT in schools, its effects on student learning and attainment, and hindrances that prevent its successful use (e.g. Becker, 1993; Butzin, 1992; Cafolla \& Knee, 1999; Cradler, 1999; Kozma \& Croninger, 1992). While some researchers have indicated the benefits of integrating ICT into education (e.g. Holinga, 1999; Taylor, 1992; Wiburg, 1997), others have found that applications of ICT in the classroom conferred little or no positive improvement in student attainment (e.g. Slavin, 1991; Stevens, 1992). Picciano (1998), on the other hand, observed that the benefits that ICT integration confers on student attainment are not uniform at all grade levels.

While Baily (1997) suggested that the foci of ICT application should be teaching and learning due to its potential use in the classroom, Levinson (1990) pointed out that in addition to providing support in teaching and learning, ICT may be used to alleviate common problems in school such as teacher shortage and high costs of education. Technology could also create new solutions to cope with the spectrum of needs that arise in the classroom in this information age (Krajcik, Soloway, Blumenfeld, \& Marx, 1998).

Given the enormous potential of ICT to impact upon education, it is imperative that factors that influence the success of ICT integration efforts be explored. Many researchers have identified effective leadership as a key ingredient of, and vitally important to, the success of any innovation in education (e.g. Bennett, 1996; Fullan, 1993). In particular, Becker (1993) contends that leadership is even more critical for successful integration of ICT in schools today. Rieber and Welliver (1998) also recognise that effective leadership is needed to enhance the transformation of our education system by taking advantage of the potential of ICT. Others go so far as to say that the success or failure of integration efforts rests on the shoulders of school leaders (e.g. Salzano, 1992). Substantiating the view that leadership is a critical factor in ICT integration efforts, Lockard, Abrams, and Mary (1990) explain that ICT integration is an enormous task that entails considering many issues and making many decisions. Agreeing, Dede (1992) points out that as leaders influence, make decisions, provide support, and model behaviour, the possible impact leadership can have upon successful ICT integration is obvious.

Having identified leadership as a key factor that can potentially influence ICT integration, it is important to examine the kind of leadership that is particularly relevant to the current climate of change in schools known as transformational leadership (Leithwood, 1994). The concepts and constructs of the theory of transformational leadership, whose origins are usually traced to the work of James McGregor Burns (Burns, 1978), have been extensively studied and developed in noneducational settings (e.g. Bass, 1985; Bass \& Avolio, 1993) and utilized to study the impact of leaders on organisational performance (Bennis \& Nanus, 1985; DePree, 1989; Senge, 1990; Tichy \& Devanna, 1986). The principles and practices of transformational leadership have also been explored, adapted and applied to the field of education (e.g. Brown, 1993; Leithwood, 1994; Sergiovanni, 1990) and are well supported by empirical research (Fisher, 1994; Jantzi \& Leithwood, 1996; Lam, 2002; Leithwood \& Jantzi, 2000; Yu, Leithwood \& Jantzi, 2002). Some experts have in fact concurred that practices of transformational leadership do contribute to the implementation of innovations in schools (e.g. Yukl, 1994; Leithwood, 1994).

While the effects of transformational leadership on organisational conditions and student engagement with school (Leithwood \& Jantzi, 2000) and on teachers' commitment (Yu et al., 2002) have been researched, no study has been conducted to examine the relationship between transformational leadership and the integration of ICT in teaching. The purpose of this paper 
therefore is to field-test a questionnaire developed to investigate teachers' perceptions of the positive influence of transformational leadership practices on integration of ICT into teaching. This is a strand of a principal study that investigates factors that impact upon successful ICT integration in schools in Singapore.

As mentioned earlier, the theory of transformational leadership was originally developed in non-educational contexts. The present study adopts a recent model of transformational leadership by Leithwood, Jantzi, and Steinbach (1999) which was developed based on empirical research adapting conceptions of transformational leadership in school settings (Leithwood, 1994; Leithwood \& Steinbach, 1995). In the theory of transformational leadership, it is the agency of the principal that matters in how the model of transformational leadership is meant to operate. In the present investigation, leaders therefore refer to school principals.

\section{THEORETICAL FRAMEWORK}

As pointed out by Leithwood and Jantzi (2000), the challenges of school restructuring such as high degrees of uncertainties about educational ends and means and a desire to professionalise teaching have been cited as reasons for advocating a relatively recent move from instructional to transformational forms of school leadership which have now become the subject of systematic empirical inquiry in school contexts. Although Burns (1978) and Bass (1985) did not base their work on transformational leadership in schools, there is evidence of similarities in such leadership whether it is in a school setting or in a business environment (Leithwood \& Jantzi, 1990; Leithwood, 1994; Jantzi \& Leithwood, 1996).

However, current literature reveals considerable variation in the conceptualisation of transformational school leadership. While some researchers (e.g. Kowalski \& Oates, 1993) accept Burns' (1978) original claims that transformational leadership represents the transcendence of self-interest by both leader and led, others work on a spectrum of various modification of Burns' (1978) theory. Leithwood (1994), for instance, built on Bass' (1985) two-factor theory in which transformational and transactional leadership represent opposite ends of the leadership continuum. This model of transformational leadership was developed based on a series of research studies, including factor analytic studies, in schools (Leithwood, 1994; Jantzi \& Leithwood, 1996; Leithwood et al., 1999; Leithwood et al., 2000) and describes three broad clusters of leadership practices, each of which includes several more dimensions:

- Setting directions includes building a shared vision, developing consensus about goals and priorities, and creating high performance expectations.

- Developing people includes providing individualised support, offering intellectual stimulation, and modelling important values and practices.

- Redesigning the organisation includes building a collaborative culture, creating and maintaining shared decision-making structures and process, and building relationships with parents and the wider community.

Based on these constructs that form the dimensions of transformational leadership, Leithwood (1994) developed the Nature of School Leadership Survey (NSLS). Studies have been conducted to illustrate how each of these practices have been carried out in school settings (Leithwood et al., 1999), describe the thinking and problemsolving processes used by transformational school leaders (e.g. Leithwood \& Steinbach, 1995), and report the effects of this new form of leadership on a wide array of organisational and student outcomes when exercised by principals (Leithwood, Tomlinson \& George, 1996; Leithwood et al., 1999).

In a nutshell, for Leithwood (1994), the transformational leadership process is all about 
helping to define a cultural identity, using symbolic language and rituals to reinforce that cultural identity, and ensuring that a school is responsive to changing circumstances in its environment. It also requires a capacity to engage others in a commitment to change. Consistent with Leithwood's findings regarding the potential of transformational leadership are the ideas of Sergiovanni (1990) who proposed that transformational leadership for schools requires the harnessing of social and interpersonal potential in addition to demonstrations of expert knowledge about education and schooling. The emphasis is also on modeling important goals and behaviors and articulating and strengthening enduring values, beliefs and cultural strands that will allow the school to develop a unique identity over time in continuous efforts to build excellent schools which society demands today (Sergiovanni, 1990).

Empirical research on transformational school leadership has been dominated by efforts to discover leader behaviours or practices that contribute significantly to valued organisational conditions and outcomes (e.g. Hallinger \& Heck, 1996) and that is not without good reasons. Studies such as that by Leithwood and Steinbach (1995), which expanded the research to inquire about internal cognitive and affective characteristics giving rise to leader practices, do seem to generate knowledge which is of direct use in improving school leader effects. There is now a convincing body of empirical evidence concerning the effects of the particular conception of transformational school leadership practices first formulated by Leithwood (1994) on a wide array of organisational and student outcomes when exercised by principals (Leithwood et al., 1996). It has also been found that such transformational leadership practices have a sizeable influence on teacher collaboration (Yu et al., 1995) and that significant relationships exist between aspects of transformational leadership and teachers' own reports of changes in both attitudes towards school improvement and altered instructional behaviour (Leithwood et al.,
2000). Sergiovanni's (1990) study also suggests that such leadership practices can improve student achievement. On the other hand, Sagor (1992) found that schools whose principal was transformational in leadership style had a culture conducive to school success. In a recent article, Lam (2002) covered similar ground as the present study in terms of examining the role of transformational leadership theory on school operations in diverse domains, drawing data from Asian societies.

The foregoing discussion supports this particular model of school leadership practices by Leithwood (1994) as a credible conception of transformational leadership particularly applicable to education and on which this study shall therefore focus. It is acknowledged in this study that transformational leadership should be seen, as pointed out by Mitchell and Tucker (1992), as only one part of a balanced approach to creating high performance in schools. It is useful to point out that some writers have expressed concern that transformational leadership is not necessarily democratic but in practice may actually be used as a managerial tool for influencing the organisation in accordance with the wishes of the leaders, thus betraying some of the moral dimensions of transformational leadership articulated by Burns (e.g. Allix, 2000). It is for this reason that the key components of what has been termed "authentic transformational leadership" have been identified: idealised influence, inspirational motivation, intellectual stimulation, and individualised consideration (Bass \& Steidlmeier, 1999). It shall be seen in the subsequent parts of this paper that it is authentic transformational leadership that provides the core of our theoretical discussion.

\section{METHOD}

\section{Purpose}

The purpose of this study is to field-test the Perceived Influence of Transformational Leadership on ICT Integration into Teaching Questionnaire (PITLICTQ), which we have 
developed by adapting items from NSLS to investigate teachers' perceptions of positive influence of transformational leadership practices on integration of ICT into teaching.

\section{Instrument}

Data were collected using PITLICTQ, a survey instrument comprising 50 items pertaining to influence of transformational leadership practices on integration of ICT into teaching (see Appendix). Demographic data such as age, gender and highest educational qualifications were also collected.

As mentioned earlier, the present study adopts Leithwood's (1994) conceptions of transformational leadership described in the last section and includes all dimensions of practices specified therein. Specifically, eight dimensions of leadership practices were included and a brief definition of these leadership dimensions is as follows:

1) Identifying and articulating a vision: practices aimed at identifying new opportunities for the school, and developing, articulating, and inspiring others with a vision of the future.

2) Fostering the acceptance of group goals: practices aimed at promoting cooperation among staff members and assisting them to work together toward common goals.

3) Providing individualised support: indications of respect for staff members and concern about their personal feelings and needs.

4) Offering intellectual stimulation: challenges to staff members to re-examine some of the assumptions about their work and rethink as to how it can be performed;

5) Providing an appropriate model: setting examples for staff members to follow that are consistent with the values leaders espouse.

6) Creating high performance expectations: behaviours that demonstrate leaders' expectations for excellence, quality, and high performance on the part of the staff.

7) Strengthening school culture: behaviours on the part of leaders aimed at developing shared norms, values, beliefs, and attitudes among staff.

8) Building collaborative structure: providing opportunities for staff to participate in decision-making about issues that affect them and for which their knowledge is crucial.

Items in the PITLICTQ are statements adapted from those in the NSLS and are distributed among the eight dimensions as described above. Using a six-point Likert scale ("strongly disagree" = 1; "disagree" $=2$; "slightly disagree" $=3$; "slightly agree" = 4; "agree" = 5; "strongly agree" = 6), Part 1 asks respondents to indicate, for each statement, the intensity of their agreement that leadership practices by school leaders as described in the statement will have a positive influence on the integration of ICT into teaching in secondary schools in Singapore. Most of the statements from the NSLS were used without alteration. Others were modestly adapted to better reflect local context.

Applying quantitative methods of data analysis in research of this nature is commonplace as is seen in studies such as that by Lam (2002). Also acknowledged in this study is the debate among some statisticians that attitude rating may not meet the strict criteria of interval data, and that the application of the Pearson correlation coefficient would therefore be inappropriate in this case, while others agree to the contrary.

\section{Sample}

Data for this study came from a survey in 2005 of 80 randomly selected secondary school teachers. The ages of the 80 respondents (48 female, 32 male) range from 21 to 45 years old with the median age range being 25-29 years. The median age range of serving secondary teachers in Singapore is 35-39 years. Most of the respondents (78\%) had at least five years of formal teaching experience in a secondary school in Singapore. Respondent confidentiality was ensured and clearly communicated to the participants. Results of data analysis were later presented to the participants. 
Table 1.

Means, Standard Deviations and Reliabilities: Dimensions of Transformational Leadership of the PITLICTQ

\begin{tabular}{lccc}
\hline & Mean & SD & Reliability \\
\hline Transformational Leadership & & & \\
Developing a widely shared vision for the school & 4.52 & 0.58 & 0.82 \\
Building consensus about school goals and priorities & 4.47 & 0.57 & 0.85 \\
Providing individualized support & 5.07 & 0.51 & 0.80 \\
Providing intellectual stimulation & 4.71 & 0.53 & 0.93 \\
Modelling behaviour & 4.81 & 0.62 & 0.92 \\
Holding high performance expectations & 4.45 & 0.64 & 0.76 \\
Strengthening school culture & 4.82 & 0.46 & 0.72 \\
Building collaborative structures & 4.68 & 0.57 & 0.75 \\
\hline
\end{tabular}

It was noted that the views of these 80 teachers may not be entirely representative of those of the overall target population of the research, namely secondary teachers, as a whole. While the above limitation certainly needs to be considered when interpreting the results of this study, as the purpose of the study is to field test the instrument PITLICTQ, it was decided that such a sample could be used.

\section{Data Analysis}

Table 1 reports the mean ratings and standard deviations of responses for each set of items measuring dimensions of transformational leadership on the survey. The reliabilities (Cronbach's alpha) for each of the scales measuring the eight dimensions of transformational leadership, based on Leithwood's (1994) model, included in the framework are also given.

The reliabilities of the eight subscales of the PITLICTQ are all within an acceptable range $(0.72$ to 0.93$)$. The reliability of the PITLICTQ was 0.96 (see Table 1). As a composite variable, transformational leadership received a mean rating of 4.71 (on a six-point scale). All of the eight dimensions of transformational leadership received very similar mean ratings (in the 4.45-5.07 range).
These results suggest that teachers generally agreed that all of the eight dimensions of transformational leadership practices do have positive influence on integration of ICT into teaching.

Note that while in this study high performance expectations received the lowest mean rating of 4.45; in various studies (e.g. Jantzi \& Leithwood, 1996; Leithwood \& Jantzi 1997), teachers most strongly perceived this set of leadership practices to be in evidence more than any of the others. This seems to suggest that while having high expectations on the part of the principal is commonplace, it does not necessarily translate to a motivation for teachers to integrate ICT into teaching. The standard deviations associated with all eight leadership dimensions range from 0.42 to 0.64 . This indicates a small variation in the perceptions of respondents.

The above findings contrast with those of recent studies (e.g. Leithwood \& Jantzi, 1997) which have reported a low level of agreement among teachers that principals made much effort to clarify school vision or to build consensus about school goals and that teachers disagreed that principals had a high priority to change teachers' values, although they invited teachers' collaboration in the implementation of change. In a study which examined the effects of transformational leadership 
on teachers' commitment to change, Yu et al. (2002) found that though the teachers surveyed agreed that principals intended to provide intellectual stimulation, the teachers disagreed that principals were professional enough to help teachers further develop themselves professionally. Furthermore, there was a low level of agreement that their support for teachers was strong and extensive enough; the support mainly being confined to the area of teachers' professional development. Also, teachers only slightly agreed that their principals provided leadership in building collaborative structures in schools (Yu et al., 2002).

Among the 50 items measuring transformational leadership, no item had a mean rating lower than the scale mid-point. The lowest mean rating reported was the item about expecting teachers to be effective innovators (Mean $=4.03, \mathrm{SD}=0.82$ ) which is part of the scale measuring high performance expectations. On the other hand, four items received a mean rating above 5.0. These items were part of the three scales about providing individualised support, modeling behavior, and strengthening school culture. The item with the highest mean rating was: Are open and genuine in dealing with staff and students (mean $=5.45, \mathrm{SD}$ $=0.63$ ). The other three items are:

- provide resources to support teachers' professional development $(\mathrm{M}=5.41, \mathrm{SD}$ $=0.68)$;

- take teachers' opinion into consideration when initiating actions that affect their work $(\mathrm{M}=5.23, \mathrm{SD}=0.61)$;

- show respect for teachers by treating them as professionals $(\mathrm{M}=5.13, \mathrm{SD}=0.55)$

These findings came as no surprise as previous research and observations do point to the importance of support and respect on the part of the leader when technology integration initiatives are implemented (Kearsley \& Lynch, 1996). In particular, many researchers have suggested that the lack of high quality teacher training is a major factor impeding the integration of technology into education (Stoddart \& Neiderhauser, 1993).

Table 2 shows Pearson-product correlations estimating the strength of relationships between

Table 2.

\section{Correlation matrix: Dimensions of Transformational Leadership of the PITLICTQ}

\section{Dependent variables}

Independent Dimensions of transformational leadership

\begin{tabular}{|c|c|c|c|c|c|c|c|c|c|}
\hline Variables & eader & Vision & oal & ort & $\begin{array}{c}\text { Stimula- } \\
\text { tion }\end{array}$ & Iodel & $\begin{array}{l}\text { Expecta- } \\
\text { tion }\end{array}$ & are & are \\
\hline Leader & 1.000 & 0.001 & 0.911 & & $0.949 * *$ & $0.865^{* *}$ & $0.659 * *$ & $0.766^{* *}$ & $0.688 * *$ \\
\hline Vision & $0.887 * *$ & 1.000 & $0.912 * *$ & $0.431 *$ & $0.834 * *$ & $0.694 * *$ & $0.671 * *$ & $0.646^{* *}$ & $0.517 * *$ \\
\hline Goal & $0.917 * *$ & $0.912 * *$ & 1.000 & $0.478 *$ & $0.816^{* *}$ & $0.776 * *$ & $0.599 * *$ & $0.658 * *$ & $0.515^{* *}$ \\
\hline & & & & & & & & & $0.496 *$ \\
\hline tim & $0.949 * *$ & 0.834 & 0.816 & & 1.000 & $0.717 *$ & $0.792 * *$ & $0.723 * *$ & $0.664 * *$ \\
\hline Model & $0.865^{* *}$ & $0.694 * *$ & $0.776^{* *}$ & $0.486^{*}$ & $0.717 * *$ & 1000 & $0.413^{*}$ & $0.697 * *$ & $0.633 * *$ \\
\hline Expectation & $0.659 * *$ & $0.671 * *$ & $0.599 * *$ & $0.412 *$ & $0.792 * *$ & $0.413^{*}$ & 1.000 & $0.442 *$ & $0.465^{*}$ \\
\hline Culture & $0.766^{* *}$ & $0.646^{* *}$ & $0.658^{* *}$ & $0.479 *$ & $0.723 * *$ & $0.697 * *$ & $0.442 *$ & 1.000 & $0.684 * *$ \\
\hline Structure & $0.688 * *$ & $0.517 * *$ & $0.515^{* *}$ & $0.496^{*}$ & $0.664 * *$ & $0.633 * *$ & $0.465^{*}$ & $0.684 * *$ & 1.000 \\
\hline
\end{tabular}

Notes: *Pearson correlation is significant at the 0.05 level (2-tailed); **Pearson correlation is significant at the 0.01 level (2-tailed) 
dimensions of transformational leadership. All eight dimensions of transformational leadership are significantly strongly correlated with each other (at $5 \%$ level), suggesting that strengthening one dimension might help strengthen other dimensions.

Though the eight dimensions of transformational leadership seem conceptually distinct, quantitative tests of such distinctiveness in studies such as that by Leithwood and Jantzi (2000) have suggested otherwise. Factor analysis using principal components extraction with varimax rotation was therefore used in the present study to analyze the individual items rating the influence of transformational leadership on ICT integration to estimate the number of factors measured by the specific items. As a result of this analysis, eleven factors explaining 88.7 percent of the variance were extracted. Factor 1 had an eigenvalue of 16.78 and explained 33.5 percent of the variance. Factor 2 had an eigenvalue of 5.75 and explained only a further 12.7 percent of the variance. Thirty-one of the items loaded on Factor 1 with loading ranging from moderate to high (0.61-0.87). The remaining 11 items loaded rather evenly on the other 9 factors, with low to moderate strengths ranging from 0.48 to 0.71 . Factor 1 attracted all the items from the dimension modeling behavior. Items not attracted by Factor 1 distributed quite evenly among the other seven dimensions.

\section{CONCLUSION}

The purpose of this study has been to field-test PITLICTQ, an instrument designed to investigate whether transformational leadership positively influence teachers to integrate ICT into teaching. Results of data analysis in this study suggest that secondary school teachers generally agreed that all of the eight dimensions of transformational leadership practices included in this study have positive influence on integration of ICT into teaching. While these teachers agreed in particular that being open and genuine in dealing with staff and students would have a positive influence on teachers' integration of ICT into teaching, the level of agreement as to whether having high expectations for teachers' professional growth and students' performance positively influences ICT integration was low.

Findings of the present study, together with the literature review presented in the Discussion section above, suggest that a lot more has to be done by school leaders to be transformational in their role in fully integrating ICT into the curriculum and, in a wider context, in managing change. Leaders in schools must first of all be concerned with the development of a clear and appealing vision. Appealing to a universal need in humans to feel good about themselves, the vision for a school, containing an idealistic picture of where the school is headed, should empower individuals and serve as a source of self-esteem and common purpose (Sergiovanni, 1990). As asserted by Yukl (1994), the vision must be crafted and explicated by and for all stakeholders and must emerge from a common understanding of current reality.

Based on the data collected, the reliability of PITLICTQ was very high (0.96) and the eight dimensions strongly correlated with each other. The instrument PITLICTQ developed in this study does therefore seem to be a viable measure of teachers' perception of the influence of transformational leadership practices on ICT integration. Further studies should be conducted to further validate the PITLICTQ. Exploratory and confirmatory factor analyses on items included in the various scales should also be carried out in addition to factor analysis using principal components extraction with varimax rotation to assess construct validity.

The present study has used a particular form of Transformational Leadership, namely that as defined by the work of Leithwood (1994), to construct a questionnaire about teacher perspectives on the use of ICT in schools. Given the complexity of school management, this model as it is may not be sufficient to enable us to fully describe, understand, and explain the role of leadership in the context of ICT integration. Indeed, transformational leadership is about the organisation and so is contingent upon rather than 
integrated with teaching and learning. The optimism and normality of this model needs to be further challenged in future studies. Possibilities for further enquiry could include: (a) a wider sample of respondents (for instance, one might expect longserving teachers to be less well-disposed towards incorporating ICT into their teaching than a new generation of teachers who are relatively more well versed in ICT); (b) conception of the transformational leadership role of heads of department in integrating ICT into teaching (the present study considered the influence of transformational leadership practices of only the principal so one might consider inter-relating the principal with other role incumbents), as well as (c) envisioning whole-school leadership role at the senior management level. Future in-depth qualitative studies should also be conducted to achieve theoretical triangulation. For example, indepth interviews could be conducted to provide fuller explanation of the interesting patterns that have emerged from the quantitative data analysis.

Other limitations of this study include those pertaining to the instrument used in the field test to determine the impact of transformational leadership on ICT integration in that the items of the instrument may not be discriminating enough to warrant substantial conclusions or observations that a transformational type of leadership is indeed the better way of doing ICT integration. The instrument may not adequately show how a teacher responding to items of the instrument is able to make a clear assessment of the problem in question as the instrument items deal with general aspects of transformational leadership and may be applied to any type of project. Furthermore, the instrument does not have specific items dealing with the principal's process of ICT integration. Future studies could address these limitations by including in the questionnaire items that are specific to ICT integration and items that enable a respondent to provide data on the leadership practices which were found to be helpful or not helpful in this project so that the data is gathered from the ground up. The kind of leadership (which may not necessarily be transformational) which is effective for ICT integration should also be examined in a more critical way.

It is also acknowledged that while it is perhaps easier to make some links between transformational leadership and cultures of change, given that the intricate relationships that exist between leadership and school culture are widely documented in the current literature, more work needs to be done to establish the links between transformational leadership and the integration of ICT into teaching. Furthermore, it cannot be assumed that dispositions towards one area of change in a school would necessarily mean similar dispositions to all aspects of change. There is therefore a need to determine in future studies which feature of the change is influenced by practice of transformational leadership and the precise contribution transformational leadership makes in the context of ICT integration.

\section{REFERENCES}

Allix, N.M. (2000). Transformational leadership: Democratic or despotic? Educational Management \& Administration 28 (1), 7-20. Baily, G. D. (1997). What technology leaders need to know: The essential top 10 concepts for technology integration in the $21^{\text {st }}$ century. Learning \& Leading with Technology, 25(1), 57-62.

Bass, B. \& Steidlmeier, P. (1999). Ethics, character and authentic transformational leadership behaviour. Leadership Quarterly, 10 (2), 181217.

Bass, B. M. (1985). Leadership and performance beyond expectations. New York: The Free Press.

Bass, B. M. \& Avolio, B. J. (1993). Transformational leadership: A response to critics. In M. M. Cheners \& R. Ayman (Eds.), Leadership theory and research: Perspective and directions (pp. 49-80), San Diego, CA: Academic Press.

Becker, H. J. (1993). Instructional computer use: Findings from a national survey of school and 
teacher practices. The Computing Teacher, 20(7), 6-7.

Becker, H. J. (1993). Teaching with and about computers in secondary school. Communication of the Association for Computing Machinery, 36(5), 69-72.

Bennett, C. K. (1996). Schools, technology, and education leadership: A framework for change. NASSP, 80 (577), 57-65.

Bennis, W. G., \& Nanus, B. (1985). Leaders: The strategies for taking charge. New York: Harper \& Row.

Brown, J. (1993). Leadership for school improvement. Emergency Librarian, 20(3), 8-20.

Burns, G. M (1978). Leadership. New York: Harper \& Row.

Butzin, S. (1992). Integrating technology into the classroom: Lessons from the project CHILD experience. Phi Delta Kappan, 74(4), 330333.

Cafolla, R., \& Knee, R. (1999). Factors limiting technology integration in education: The leadership gap. Retrieved November 18, 2004 from http://www.coe.uh.edu/insite/elec-pub/ html1995/152.htm.

Cradler, J. (1999). Implementing technology in education: Recent findings from research and evaluation studies Retrieved May 3, 2005 from http://www.education.lanl.gov/ RES OUR CES/Model_Nets / t e a m/ team fwl.html.

Dede, C. (1992). Leadership without followers. The Computing Teacher, 20(6), 9-11.

DePree, M. (1989). Leadership is an art. New York: Doubleday.

Education, Ministry of, (1997). Speech by RADM Teo Chee Hean, Minister for Education and 2nd Minister for Defence at the launch of the Masterplan for IT in Education on Monday 28 April 97 at Suntec city at 10 am. Retrieved June 28, 2003, from http://www1.moe.edu.sg/ iteducation/masterplan/summary0.htm

Eib, B. J., \& Mehlinger, H.D. (1998). Technology in education: From segregation to integration. The High School Magazine, 6(1). Retrieved
March 12, 2005, from http://nassp.org/ publications/hsmag/teched.htm.

Fisher, J. L. (1994). Reflections on transformational leadership. Educational Record, 75(3), 54-60.

Fullan, M. G. (1993). Change forces: Probing the depths of educational reform. London: Falmer Press.

Hallinger, P. and Heck, R. (1996). Reassessing the principal's role in school effectiveness: A review of empirical research 1980-1995. Education Administration Quarterly, 32(1), 5-44.

Holinga, M. J. (1999). Project LINCOL'N'. Learning \& Leading with Technology, 26(7), 54-60.

Jantzi, D. \& Leithwood, K. (1996). Toward an explanation of teachers' perceptions of transformational school leadership. Educational Administration Quarterly, 32(4), 312-538.

Kearsley, G. \& Lynch, W. (1996). Educational technology: Leadership perspectives. Englewood Cliffs, NJ: Educational Technology Publications.

Kowalski, J. \& Oates, A. (1993). The evolving role of superintendents in school-based management. Journal of School Leadership, 3(4), 380-390.

Kozma, R. B., \& Croninger, R. G. (1992). Technology and the fate of at-risk students. Education and Urban Society, 24(4), 440453.

Krajcik, J., Soloway, E., Blumenfeld, P., \& Marx, R. (1998). Scaffolder technology tools to promote teaching and learning science. In C.Dede (Ed.), ASCD year book (pp. 31-45). Alexandria, VA: Association for Supervision and Curriculum Development.

Lam, J. (2002). Defining the effects of transformational leadership on organisational learning: a cross-cultural comparison. School Leadership \& Management, 3(4), 439-452.

Leithwood, K. (1994). Leadership for school restructuring. Educational Administration Quarterly, 30, 498-518.

Leithwood, K. \& Jantzi, D. (1990). Transformational leadership: How principals can 
help reform school cultures. School Effectiveness and School Improvement, 1(4), 249-280.

Leithwood, K. \& Jantzi, D. (1997). Explaining variation in teachers' perceptions of principals' leadership: A replication. Journal of Educational Administration, 30(4), 312-331.

Leithwood, K. \& Steinbach, R. (1995). Expert problem solving: Evidence from school and district leaders. New York: SUNY Press.

Leithwood, K. A. \& Jantzi, D. (2000). The effects of transformational leadership on organisational conditions and student engagement with school. Journal of Educational Administration, 38(2), 112-124.

Leithwood, K., Jantzi, D., \& Steinbach, R. (1999). Changing leadership for changing times. Buckingham, UK: Open University Press.

Leithwood, K., Tomlinson, D., \& Genge, M. (1996). Transformational school leadership. In K. Leithwood, J. Chapman, D. Corson, P. Hallinger, \& A. Hart (Eds.), International handbook of educational leadership and administration (pp. 785-840). Dordrecht, Netherlands: Kluwer Academic Publishers.

Levinson, E. (1990). Will technology transform education or will the schools co-opt technology?. Phi Delta Kappan, 72(2), 121-126.

Lockard, J., Abrams, P. D., \& Mary, W. A. (1990). Microcomputers for educators ( $2^{\text {nd }}$ Ed.). Northen Illinois University.: Harper Collins.

Mitchell, D. E. \& Tucker, S. (1992). Leadership as a way of thinking. Educational Leadership, 49(5), 30-35.

Picciano, A. G. (1998). Educational leadership and planning for technology ( $2^{\text {nd }}$ ed.). Upper Saddle River, NJ: Prentice-Hall Inc.

Rieber, L. \& Welliver, P. (1998). Infusing educational technology into mainstream educational computing', International Journal of Instructional Media, 16(1), 21-31.

Sagor, R. D. (1992). Three principals who make a difference. Educational Leadership, 49(5), 13-18.
Salzano, J. (1992, March 16-20). The key to successful computerization is through good trainers. Paper presented at the International Conference on Technology and Education. Paris, France.

(ERIC Document Reproduction Service No. ED363698)

Senge, P. J. (1990). The fifth discipline: The art and practice at the learning organization. Toronto: Doubleday.

Sergiovanni, T. J. (1990). The principalship: A reflective practice perspective. Toronto: Allyn and Bacon.

Slavin, R. E. (1991). Reading effects of IBM's "Writing to Read" program: A review of evaluations. Educational Evaluation and Policy Analysis, 13(1), 1-11.

Stevens, D. J. (1992). Why computers in education may fail. Education, 104(4), 370-376.

Stoddart, T. \& Niederhauser, D (1993). Technology and educational change. Computers in the Schools, 9(2/3), 5-21.

Taylor, L. (1992). Teaching mathematics with technology. Arithmetic Teacher, 40(3), 187191.

Tichy, N. M. \& Devanna, M. A. (1986). The transformational leader. New York: John Wiley.

Wiburg, K. M. (1997). The dance of change: Integrating technology in classrooms. In D. L. Johnson, C. D. Maddux, \& L. Liu (Ed.), Using technology in the classroom (pp. 171-184), New York: The Haworth Press, Inc.

Yu, H., Leithwood, K., \& Jantzi, D. (2002). The effects of transformational leadership on teachers; commitment to change in Hong Kong. Journal of Educational Administration, 40(4), 368-389.

Yukl, G. (1994). Leadership in organizations $\left(3^{\text {rd }}\right.$ Ed.). Englewood Cliffs, NJ: Prentice-Hall. 


\section{APPENDIX}

\begin{tabular}{|c|c|c|c|c|c|c|c|}
\hline & & $\begin{array}{l}\mathbf{S} \\
\mathbf{D}\end{array}$ & & & & & $\begin{array}{l}\mathbf{S} \\
\mathbf{A}\end{array}$ \\
\hline 1 & $\begin{array}{l}\text { Regularly encourages teachers to evaluate their progress } \\
\text { towards achieving the school goals }\end{array}$ & 1 & 2 & 3 & 4 & 5 & 6 \\
\hline 2 & $\begin{array}{l}\text { Excites teachers with a vision of what they may be able to } \\
\text { accomplish if they work together to change their practices }\end{array}$ & 1 & 2 & 3 & 4 & 5 & 6 \\
\hline 3 & $\begin{array}{l}\text { Rarely takes teachers' opinion into account when making } \\
\text { decisions }\end{array}$ & 1 & 2 & 3 & 4 & 5 & 6 \\
\hline 4 & Leads by doing rather than simply telling & 1 & 2 & 3 & 4 & 5 & 6 \\
\hline 5 & $\begin{array}{l}\text { Provides resources to support teachers' professional } \\
\text { development }\end{array}$ & 1 & 2 & 3 & 4 & 5 & 6 \\
\hline 6 & $\begin{array}{l}\text { Encourages teachers to re-examine some basic assumptions } \\
\text { they have about their work }\end{array}$ & 1 & 2 & 3 & 4 & 5 & 6 \\
\hline 7 & $\begin{array}{l}\text { Gives high priority to developing within the school a shared set } \\
\text { of values, beliefs and attitudes related to education }\end{array}$ & 1 & 2 & 3 & 4 & 5 & 6 \\
\hline 8 & $\begin{array}{l}\text { Distributes leadership broadly among the staff, representing } \\
\text { various viewpoints in leadership positions }\end{array}$ & 1 & 2 & 3 & 4 & 5 & 6 \\
\hline 9 & Has high expectations for teachers as professionals & 1 & 2 & 3 & 4 & 5 & 6 \\
\hline 10 & Maintains a very low profile & 1 & 2 & 3 & 4 & 5 & 6 \\
\hline 11 & $\begin{array}{l}\text { Provides teachers with a process through which they generate } \\
\text { school goals }\end{array}$ & 1 & 2 & 3 & 4 & 5 & 6 \\
\hline 12 & Is a source of new ideas for teachers' professional learning & 1 & 2 & 3 & 4 & 5 & 6 \\
\hline 13 & Holds high expectations for students & 1 & 2 & 3 & 4 & 5 & 6 \\
\hline 14 & Gives teachers a sense of overall purpose & 1 & 2 & 3 & 4 & 5 & 6 \\
\hline 15 & $\begin{array}{l}\text { Takes teachers' opinion into consideration when initiating } \\
\text { actions that affect their work }\end{array}$ & 1 & 2 & 3 & 4 & 5 & 6 \\
\hline 16 & Shows respect for teachers by treating them as professionals & 1 & 2 & 3 & 4 & 5 & 6 \\
\hline
\end{tabular}


17 Stimulates teachers to think about what they are doing for their students

18 Ensures that teachers have adequate involvement in decision making related to curriculum programmes and teaching

19 Supports an effective committee structure for decision making

20 Makes an effort to know students

21 Sets a respective tone for interaction with students

22 Encourages teachers to pursue their own goals for professional development

23 Encourages ongoing teacher collaboration for implementing new programmes and practices

24 Helps clarify the specific meaning of the school's vision in terms of its practical implications for curriculum programmes

25 Encourages teachers to develop/review individual professional growth goals consistent with school goals and priorities

26 Expects teachers to engage in ongoing professional growth

27 Displays energy and enthusiasm for their own work

28 Lacks awareness of the unique needs and expertise of individual teachers

29 Encourages teachers to evaluate their practices and refine them as needed

30 Expects teachers to be effective innovators

31 Demonstrates a willingness to change their own practices in the light of new understandings

32 Encourages teachers to try new practices consistent with their interests

33 Rarely refers to school goals when they are making decisions related to changes in programmes and practices

\begin{tabular}{|c|c|c|c|c|c|}
\hline 1 & 2 & 3 & 4 & 5 & 6 \\
\hline 1 & 2 & 3 & 4 & 5 & 6 \\
\hline 1 & 2 & 3 & 4 & 5 & 6 \\
\hline 1 & 2 & 3 & 4 & 5 & 6 \\
\hline 1 & 2 & 3 & 4 & 5 & 6 \\
\hline 1 & 2 & 3 & 4 & 5 & 6 \\
\hline 1 & 2 & 3 & 4 & 5 & 6 \\
\hline 1 & 2 & 3 & 4 & 5 & 6 \\
\hline 1 & 2 & 3 & 4 & 5 & 6 \\
\hline 1 & 2 & 3 & 4 & 5 & 6 \\
\hline 1 & 2 & 3 & 4 & 5 & 6 \\
\hline 1 & 2 & 3 & 4 & 5 & 6 \\
\hline 1 & 2 & 3 & 4 & 5 & 6 \\
\hline 1 & 2 & 3 & 4 & 5 & 6 \\
\hline 1 & 2 & 3 & 4 & 5 & 6 \\
\hline 1 & 2 & 3 & 4 & 5 & 6 \\
\hline 1 & 2 & 3 & 4 & 5 & 6 \\
\hline
\end{tabular}


34 Stimulates discussion of new ideas relevant to school directions

Facilitates effective communication among staff

Establishes working conditions that inhibit staff collaboration for professional growth and planning

Communicates school vision to staff and students

Encourages the development of school norms supporting openness to change

Shows favouritism toward individuals or groups

Facilitates opportunities for staff to learn from each other

Reinforces isolation of teachers who have special expertise

Provides an appropriate level of autonomy for teachers in their own decision making

Provides moral support by making teachers feel appreciated for their contributions to the school

Helps us understand the relationship between the school's vision and the ministry's initiatives

Models problem solving techniques that teachers can readily adapt for work with their colleagues and students

Promotes an atmosphere of caring and trust among staff

Symbolises success and accomplishment within the profession

Supports the status quo at the expense of being at the cutting edge of educational change

Works toward whole staff consensus in establishing priorities for school goals 